OCCASIONAL REVIEW

\title{
Matrix metalloproteinases in destructive pulmonary pathology
}

\author{
P T G Elkington, J S Friedland
}

Thorax 2006;61:259-266. doi: 10.1136/thx.2005.051979

Matrix metalloproteinases (MMPs) are a family of proteolytic enzymes that have a number of important physiological roles including remodelling of the extracellular matrix, facilitating cell migration, cleaving cytokines, and activating defensins. However, excess MMP activity may lead to tissue destruction. The biology of MMP and the role of these proteases in normal pulmonary immunity are reviewed, and evidence that implicates excess MMP activity in causing matrix breakdown in chronic obstructive pulmonary disease (COPD), acute respiratory distress syndrome (ARDS), sarcoidosis, and tuberculosis is discussed. Evidence from both clinical studies and animal models showing that stromal and inflammatory cell MMP expression leads to immunopathology is examined, and the mechanisms by which excess MMP activity may be targeted to improve clinical outcomes are discussed.

See end of article for authors' affiliations

......................

Correspondence to: Dr P T G Elkington, Department of Infectious Diseases, Imperial College, Hammersmith Hospital, Du Cane Road, London W12 ONN, UK; p.elkington@ imperial.ac.uk

Received 23 August 2005 Accepted 1 October 2005
$\mathrm{N}$ ormal lung function requires alveolar support by the extracellular matrix (ECM). In many pulmonary diseases abnormal remodelling or destruction of the ECM occurs, leading to impaired lung function and, if extensive, death. Consideration of the biochemistry of the lung matrix predicts that the matrix metalloproteinase (MMP) family of enzymes is likely to be involved in this pathology. MMPs are proteases that collectively can degrade all components of the ECM, but also have important roles in normal immunity. ${ }^{1}$ Thus, MMPs may modulate appropriate responses to exogenous stimuli but may also contribute to immunopathology that leads to aberrant turnover of the ECM. We review the roles of MMPs in normal pulmonary immunity and discuss four diseases where excess MMP activity may contribute to pulmonary destruction: chronic obstructive pulmonary disease (COPD), the acute respiratory distress syndrome (ARDS), sarcoidosis, and tuberculosis (TB).

\section{THE PULMONARY ECM}

The pulmonary interstitium forms the mechanical scaffold of the lung, while the basement membrane supports alveolar epithelial cells and in part determines the resistance of the diffusion barrier. $^{2}$ The primary structural fibrils of the lung are type I collagen which provides tensile strength, and elastin which allows distensibility. ${ }^{3}$ Elastin fibres are usually highly stable and often last life-long. ${ }^{4}$ The alveolar wall is primarily made from type III collagen ${ }^{5}$ while the basement membrane is rich in type IV collagen. Large collagen and elastin fibres are connected by a variety of smaller fibrils. Degradation of the primary structural fibrils of the lung will therefore first involve cleavage of the cross linking fibrils to expose enzyme binding sites. ${ }^{6}$ Consequently, multiple enzymes are likely to be involved in the turnover of the ECM, and it may be impossible to specify a single protease as the critical mediator of any particular pulmonary pathology. MMP involvement in degradation of the lung ECM is predicted since fibrillar type I collagen is highly resistant to enzymatic degradation and only certain MMPs can degrade it at neutral pH. ${ }^{7}$ Furthermore, multiple MMPs are elastases and MMPs also degrade type IV collagen.

\section{MATRIX METALLOPROTEASES}

MMPs are a family of zinc dependent proteases that were initially identified in the involuting tail of tadpoles by their ability to degrade collagen. ${ }^{8}$ MMPs can be broadly classified on the basis of substrate specificity into collagenases (MMP-1, -8 and -13), gelatinases (MMP-2 and -9), stromelysins (MMP-3, -10, -11), elastases (MMP-7 and -12), and membrane type MMPs (MT-MMPs, MMP-14, -15, -16 and -17) which are surface anchored. MMP-1 (interstitial collagenase), MMP-8 (neutrophil collagenase), MMP-13 (collagenase 3), and MMP-14 (MT1MMP) can cleave the triple helix of native type I collagen, ${ }^{7}$ the primary architectural collagen of the lung. ${ }^{3}$ Elastolytic MMPs include MMP-2 (gelatinase A), MMP-7 (matrilysin), MMP-9 (gelatinase B), and MMP-12 (macrophage metalloelastase).

Since MMPs may cause significant host damage, they are tightly regulated. Firstly, they are rarely stored but require gene transcription before secretion, the exception being neutrophil MMP-8 and -9. Secondly, they are either secreted as pro-enzymes that require proteolytic cleavage or, in the case of MT-MMPs, activated intracellularly by pro-protein convertases such as furin. This processing exposes the catalytic cleft, a mechanism known as the cysteine switch. ${ }^{9}$ Thirdly, specific inhibitors of MMPs - the tissue inhibitors of metalloproteinases (TIMPs)—are

Abbreviations: MMP, matrix metalloproteinase; ECM, extracellular matrix; COPD, chronic obstructive pulmonary disease; ARDS, acute respiratory distress syndrome; TB, tuberculosis; MTb, Mycobacterium tuberculosis; BAL, bronchoalveolar lavage 
secreted which bind MMPs in a $1: 1$ manner to prevent enzymatic activity. ${ }^{10}$ The balance of MMPs to TIMPs therefore determines matrix turnover, where either an excess of MMPs or a deficit of TIMPs may result in excess ECM degradation. Finally, MMPs can be compartmentalised in close proximity to the cell.

The majority of MMPs are not expressed in normal healthy tissues but are expressed in diseased tissues that are inflamed or undergoing repair and remodelling. ${ }^{11}$ MMP expression may be upregulated by exogenous stimuli, cytokines and cellcell contact. Conversely, cytokines such as interferon (IFN)- $\gamma$ and interleukins (IL)-4 and -10 may downregulate MMP expression. Both inflammatory and stromal cells can express MMPs, although the profile is both cell and stimulus specific. For example, macrophages express a wider profile and greater quantities of MMPs than monocytes. ${ }^{12}$ Pulmonary epithelial cells may also be a significant source of MMPs as they express MMP-1, -2, -7 and $-9 . .^{13-15}$ Intracellularly, MMP secretion is primarily regulated by the prostaglandin (PG) and mitogen activated protein kinase (MAPK) signal transduction pathways. ${ }^{15-17}$

The complexity of proteinase interactions is illustrated by the manner in which MMP-9 deficiency prevents neutrophil elastase induced immunopathology. In a model of autoimmune skin disease, MMP-9 deficient mice were found to be resistant to blister formation. ${ }^{18}$ However, a direct role for MMP-9 was not identified. Instead, MMP-9 is responsible for cleaving the serpin $\alpha_{1}$-proteinase inhibitor which then results in uninhibited neutrophil elastase activity. Multiple proteases may therefore be involved in a cascade, with a single one causing the final pathology but upstream enzymes being equally critical to the process.

\section{MMPs IN PULMONARY IMMUNITY}

Although MMPs are implicated in numerous diseases characterised by abnormal turnover of the ECM such as arthritis, malignancy, and atherosclerosis, they also have multiple functions in the normal immune response. ${ }^{7}$ Therefore, before discussing how MMPs may contribute to immunopathology in specific lung diseases, we will review the biology of MMPs in pulmonary immunity.

\section{Cell migration}

The pulmonary surface is exposed to exogenous injury and, when damaged, ECM remodelling is required to allow epithelial repair. Migration of stromal and inflammatory cells occurs and MMPs are involved in this process. MMP-7 expression is increased in wounded epithelial cells and MMP7 knock-out mice have deficient epithelial cell migration during wound healing, demonstrating the functional importance of MMP activity. ${ }^{14}$ Similarly, MMP-9 accumulates at the leading edge of migrating pulmonary epithelial cells and inhibition of MMP activity prevents cell migration, suggesting that MMP-9 is also important in pulmonary epithelial repair. ${ }^{19}$ This hypothesis is supported by the observation that MMP-9 deficient mice display abnormal alveolar bronchiolisation in a bleomycin model of lung injury. ${ }^{20}$

In addition to facilitating epithelial cell migration, MMPs are involved in the matrix remodelling necessary for the egression of inflammatory cells. For example, MMP inhibition prevents the extravasation of lymphocytes across high endothelial venules. ${ }^{21}$ In an immune complex model of lung injury MMP-3 deficient mice have reduced neutrophil influx ${ }^{22}$ possibly due to the ability of MMP-3 to cleave type IV collagen, the primary collagen of the basement membrane. ${ }^{1}$ Similarly, MMP-9 null mice display reduced dendritic cell recruitment to the airways in an allergen exposure model. ${ }^{23}$ MMP activity is therefore required for both stromal and immune cell migration in the lung.

\section{Intercellular signalling}

In addition to degrading components of the ECM, MMPs may act on a variety of non-matrix substrates. MMPs can proteolytically process cytokines and chemokines to both augment and reduce their activity. For example, MMPs can both activate and inactivate pro-IL-1 $\beta$, thereby providing both positive and negative regulation. ${ }^{24}{ }^{25}$ Several MMPs can release surface bound tumour necrosis factor $\alpha$ (TNF- $\alpha$ ) by a similar mechanism to TNF- $\alpha$ converting enzyme (TACE, A disintegrin and metalloprotease (ADAM)-17) ${ }^{26}$ In addition to processing cytokines, MMPs also cleave chemokines. MMP-9 processes CXCL8 (IL-8) to a fragment with 10 times the potency of the parent molecule. ${ }^{27}$ Conversely, CCL7 (MCP-3) is cleaved from an active to an inactive form by MMP-2, and the CCL7 fragment acts as a receptor antagonist. ${ }^{28}$ This has led to the hypothesis that MMP activity may act as a tuner and amplifier of immune responses, regulating both positive and negative feedback to facilitate the appropriate influx of inflammatory cells and the timely resolution of inflammation. ${ }^{29}$

MMPs are involved in regulating chemokine activity not only by proteolytically processing them, but also by releasing them from cell surface anchors. MMP-7 knock-out mice fail to recruit neutrophils to the alveolar space in a bleomycin injury model. Neutrophils leave the circulation but become trapped in the interstitium. ${ }^{30}$ The migration deficit did not result from insufficient matrix degradation but was secondary to the failure to release a surface bound molecule, syndecan-1, which acts as an anchor for the chemokine KC. MMP-7 activity is required to cleave syndecan- 1 on pulmonary epithelial cells, thereby releasing and activating $\mathrm{KC}$, permitting $\mathrm{KC}$ to exert its biological activity and thus drive neutrophil influx.

In addition to modulating the activity of cytokines and chemokines, MMPs can mediate intercellular signalling directly. MMP-1 can cleave proteinase activated receptor 1 (PAR-1) on the cell surface, initiating a G-protein dependent intracellular signalling cascade and calcium flux. ${ }^{31}$ In a model of malignant invasion, activation of PAR-1 by MMP-1 led to increased tumour invasiveness. MMP-1 was derived from fibroblasts, not malignant cells, which shows that MMPs may modulate interactions between invading and stromal cells.

\section{Defensin activation}

In the gut MMP-7 activates the antimicrobial peptides pro- $\alpha$ defensins $^{32}$ and may play a similar role in the lung. The functional importance of $\alpha$-defensin activation is shown by the delayed clearance of bacteria from the bowel in MMP-7 deficient mice. ${ }^{32}$ MMP-7 expression in airway epithelial cells is upregulated in diseases characterised by chronic infection such as cystic fibrosis, supporting the hypothesis that MMP-7 contributes to pulmonary immunity. ${ }^{14}$ Furthermore, bacterial components alone can actively drive MMP-7 secretion from cultured pulmonary epithelial cells. ${ }^{33}$ Together with the release of anchored chemokines by MMP-7, these results have led to the hypothesis that MMP-7 secretion may be part of a generalised activation response to bacteria. ${ }^{1}$

The data outlined above indicate that MMPs play important roles in normal pulmonary immunity by facilitating cell migration, modulating chemokine and cytokine activity, activating defensins, and mediating intercellular signalling. However, extensive evidence has accumulated that altered MMP activity can lead to disease. The number of pulmonary conditions in which MMPs have been implicated in the pathology encompasses much of thoracic medicine (table 1) and so cannot be addressed within a single review. Here, we examine four conditions-COPD, ARDS, sarcoidosis, and $\mathrm{TB}$-where destruction of the pulmonary ECM is a 


\begin{tabular}{|lc|}
\hline $\begin{array}{l}\text { Table } 1 \text { Pulmonary diseases in which } \\
\text { dysregulated MMP activity is implicated in the } \\
\text { pathology }\end{array}$ \\
\hline Diseases & References \\
\hline Lung cancer & 34 (R) \\
Asthma & 35 (R) \\
COPD & $36-58$ \\
ARDS & $59-70$ \\
Sarcoidosis & $71-75$ \\
Tuberculosis & $76-88$ \\
Idiopathic pulmonary fibrosis & $73,89-93$ \\
Silicosis & 94 \\
Cystic fibrosis & $14,95,96$ \\
Pneumonia & 97 \\
Lymphangioleiomyomatosis (LAM) & 98,99 \\
Cryptogenic organising pneumonia & 100 \\
Bronchiolitis obliterans & 101,102 \\
Langerhans' cell granulomatosis & 103 \\
Radiation pneumonitis & 104 \\
\hline This list is not exhaustive. (R) denotes review article. \\
\hline
\end{tabular}

key component of the disease process, and review evidence that excessive MMP activity contributes to this pathology.

\section{CHRONIC OBSTRUCTIVE PULMONARY DISEASE}

The observation that smokers with $\alpha_{1}$-antitrypsin deficiency develop COPD provided the initial indication that a protease/ antiprotease imbalance can drive pulmonary pathology. ${ }^{105}$ Since neutrophil elastase is one of the enzymes inhibited by $\alpha_{1}$-antitrypsin, excess elastase activity was initially thought to be responsible for the destructive pathology in COPD. However, although there is considerable evidence for the involvement of neutrophil elastase in COPD, it now seems that multiple proteases acting in concert cause pathology. ${ }^{106}$ The turnover of the lung ECM will involve the interaction of several enzymes as cross linking fibrils must first be cleaved to expose the major fibres to allow their degradation. ${ }^{6}$ Since MMPs degrade all components of the ECM including type I collagen and elastin, they are likely to be involved in tissue remodelling in COPD.

\section{Animal models}

Mice that constitutively overexpress human MMP-1 develop spontaneous air space enlargement, showing that MMP-1 can drive pulmonary destruction. ${ }^{36}$ Since that report, numerous transgenic mouse models have been developed in which emphysema-like changes develop. For example, targeted overexpression of IFN- $\gamma$, IL-13, or TNF- $\alpha$ causes inflammation and air space enlargement accompanied by the upregulation of numerous proteases. ${ }^{37-39}$ Similarly, macrophage colony stimulating factor (M-CSF) deficient mice, surfactant protein $D$ deficient mice, and integrin $\alpha_{v} \beta_{6}$ deficient mice also develop air space enlargement. ${ }^{40-42}$ In all these models increased MMP activity has been demonstrated and, furthermore, mice deficient in MMP-12 are resistant to the pathological changes of cigarette smoke exposure. ${ }^{43}$ The absence of MMP inhibitors can also result in abnormal pulmonary matix turnover as TIMP-3 deficient mice spontaneously develop air space enlargement at 2 weeks of age. ${ }^{44}$

The functional importance of MMP activity in these models is confirmed by crossing emphysema developing mice with MMP-knockout mice. For example, in the IL-13 overexpression model, deficiency of MMP-9 or MMP-12 results in reduced pathological changes and less respiratory failure. ${ }^{45}$ Similarly, crossing integrin $\alpha_{\mathrm{v}} \beta_{6}$ deficient mice with MMP-12 deficient mice prevents the development of age related emphysema. ${ }^{42}$ However, these studies are limited by the lack of a functional murine orthologue of human MMP-1. The proposed orthologue, Mcol-A, has greatly reduced activity against type I collagen compared with human MMP- $1,{ }^{107}$ and in human disease MMP-1 may play a primary role, as outlined below. Secondly, in some models changes develop early in life so may result from developmental abnormalities as opposed to reflecting the exogenous insults that cause COPD in humans. ${ }^{108}$

The guinea pig presents an alternative to the mouse in the study of cigarette smoke induced lung damage and MMP activity has also been implicated in this model. Smoke exposed guinea pigs have increased pulmonary collagenase levels as analysed by gene expression, immunoreactive protein, and activity. ${ }^{46}$ This upregulation of collagenase activity is associated with a reduction in total lung collagen. Furthermore, the pathological changes are reduced by a broad spectrum MMP inhibitor, demonstrating the therapeutic potential of targeting MMPs in COPD. ${ }^{47}$

\section{Human studies}

The models described above indicate that MMP-9 and MMP12 play key roles in destructive pulmonary pathology in mice and that collagenase activity is important in guinea pigs. However, studies in patients suggest that the spectrum of MMPs in human disease may differ significantly from these models. Clinical studies are often limited by demonstrating association as opposed to causation, but clinical investigation is essential to identify which proteases are critical in pulmonary disease in man.

Alveolar macrophages from patients with COPD express more MMP-1 and -9 than those from normal volunteers, and this is associated with increased secretion of active enzymes. ${ }^{48}$ No increase in MMP-12 expression or activity was found. MMP-9 secretion is further increased in response to inflammatory stimuli. ${ }^{49}$ 50 The increased MMP-9 expression in macrophages is associated with increased MMP-9 activity in bronchoalveolar lavage (BAL) fluid..$^{51}$ Alveolar macrophages secrete several elastolytic proteases and the contribution of MMPs to elastin degradation increases with time. ${ }^{53}$

Although BAL fluid analysis provides a good indication of protease activity within the airways, it may not provide an indication of events within the interstitium where most of the tissue remodelling occurs. Also, studies using BAL fluid derived alveolar macrophages assume that they are the primary source of MMPs in emphysema, but stromal cells may make a greater contribution to ECM turnover. Immunohistochemistry does not have these limitations, and in an analysis of collagenase and gelatinase expression in COPD, MMP-1, $-2,-8$ and -9 were found to be upregulated. ${ }^{54}$ Neutrophils were identified as the primary source of MMP-8 and -9 , while MMP- 1 and -2 were expressed by macrophages and epithelial cells. ${ }^{54}$ Increased MMP-14 expression has also been demonstrated in emphysematous lungs by immunohistochemistry and by western blotting. ${ }^{55}$ In a study combining RT-PCR, ELISA, immunohistochemistry and a collagen degradation assay to analyse MMP-1, -9 and -12 , increased MMP-1 expression was observed in patients with COPD. ${ }^{56}$ Type II pneumocytes were identified as a main source of MMP-1, suggesting that inflammatory cells may not be exclusively responsible for tissue destruction in emphysema. ${ }^{56}$ MMP-1 expression correlated with increased collagenase activity in homogenised lung samples. In contrast to the BAL fluid studies, MMP-9 expression did not differ between emphysema and control samples. Again, no MMP-12 expression was found in human disease, despite the critical role for MMP-12 in the mouse model of emphysema. However, another study did show increased MMP-12 expression in smokers with COPD compared with normal smokers. ${ }^{57}$ Increased MMP-1 expression in epithelial cells of 
smokers may result from prolonged activation of the ERK mitogen activated protein kinase pathway, providing a potential regulatory point to suppress activity. ${ }^{15}$

Taking clinical and animal studies together, the evidence linking MMP-1 and MMP-9 to emphysema is the most compelling. MMP-12 is essential to cigarette smoke induced pathology in the mouse but may not be equally critical in human disease. MMP-7 has not been specifically studied in human emphysema, despite being a potent elastase secreted by human macrophages. ${ }^{109}$ The ease of detection of MMP-9 may have caused over-representation in clinical studies relative to MMPs that are more difficult to quantify. Whether MMP-9 is primarily responsible for pathology or part of the inflammatory and reparative process remains an area of debate. ${ }^{110}$ The nature of MMP biology allows MMP-9 to be both involved in the initial pathological insult when released in excess, but also to be necessary for tissue repair when secreted at appropriate levels. Studies of MMP activity may therefore give divergent results at different stages of disease evolution and lead to controversy about which MMPs are critical in pulmonary disease.

\section{ACUTE RESPIRATORY DISTRESS SYNDROME}

ARDS may result from a wide spectrum of systemic insults such as septicaemia which precipitate increased permeability of the alveolar-capillary barrier causing impairment of gas exchange. Chronically, the disease may progress to fibrotic lung injury. ${ }^{11}$ Since the alveolar basement membrane is primarily type IV collagen, MMPs are likely to be involved in the extensive ECM remodelling that occurs in ARDS. In the acute phase of ARDS increased MMP-9 levels have been identified in BAL fluid ${ }^{59-61}$ and are associated with markers of basement membrane disruption. ${ }^{60}$ However, when ARDS patients were compared to those with hospital acquired pneumonia, no increase in MMP-9 levels was found. ${ }^{62}$ Lung tissue remodelling may be exacerbated by treatment since hyperoxia upregulates collagenase and gelatinase activity in rat lungs. ${ }^{63}$ The complexity of the events in early ARDS is highlighted by the observation that not only are protease levels increased, but markers of collagen synthesis are also raised. ${ }^{61}{ }^{64}$ The response to the initial insult may therefore drive both ECM destruction and synthesis and, in some cases, may ultimately result in fibrosis.

The functional importance of MMP activity in ARDS has been investigated in animal models of acute lung injury. In an immune complex deposition model in the mouse, mice deficient in MMP-3, -9 or -12 had less severe lung injury than wild type mice. ${ }^{22}{ }^{65}$ Additionally, neutralising the inhibitor TIMP-2 exacerbates lung damage in this model, demonstrating once more that the balance between MMPs and their inhibitors is critical in determining pathological outcomes. ${ }^{66}$ Similarly, mice deficient in TIMP-3 develop worse lung injury in a model of sepsis associated with reduced collagen and fibronectin levels. ${ }^{67}$

These data indicate that MMPs may contribute to the initial lung insult in ARDS, suggesting that MMP inhibition may prevent acute lung injury. In a cardiopulmonary bypass model, inhibition of MMP and neutrophil elastase activity by a chemically modified tetracycline reduced lung injury. ${ }^{68}$ Similar protective effects by inhibiting these enzymes have been demonstrated in animal models of sepsis. ${ }^{69} 70$ Modulation of MMP activity therefore has the potential to prevent acute lung injury, but the challenge will be to give treatment sufficiently early in the course of the disease to halt the pathological cascade initiated by excessive protease activity. Furthermore, comparison between studies is difficult because of the diverse models and different MMPs investigated.

\section{SARCOIDOSIS}

Sarcoidosis is a syndrome affecting multiple organs with diverse clinical presentations. Granuloma formation is common to all disease manifestations and results in extensive ECM remodelling. Collagenase activity can be detected in the BAL fluid of patients with sarcoidosis and, when present, is associated with a lower carbon monoxide transfer factor. ${ }^{71}$ Furthermore, the decline in lung function is more rapid in collagenase positive patients. ${ }^{72}$ MMP- 8 appears to be responsible for this activity since MMP-8 levels and collagenase activity correlate. ${ }^{73}$ MMP-9 levels are also increased in the BAL fluid and induced sputum of patients with sarcoidosis, with no compensatory increase in the levels of the inhibitor TIMP-1. ${ }^{73}$ The cellular source of MMPs may primarily be multinucleate giant cells since they are highly immunoreactive for MMP-1 and $-9 .^{75}$ The pathological result of this unopposed protease activity is disruption of the basement membrane as focal damage is observed on staining for type IV collagen. ${ }^{75}$ Such data implicate MMP activity in initiating ECM breakdown and remodelling that can lead to the decline in lung function that occurs in advanced pulmonary sarcoidosis.

\section{TUBERCULOSIS}

Mycobacterium tuberculosis is one of the most successful human pathogens of all time and remains a global health crisis. ECM destruction is fundamental to the success of $M$ tuberculosis since it allows cavitation and thereby creates an immunoprivileged site within which the organism can proliferate and then spread to new hosts. ${ }^{112}$ The reduced immune surveillance of the cavity is demonstrated by the ability of less virulent pathogens such as $M$ intracellulare, $M$ xenopi, and Aspergillus fumigatus to occupy a pre-existing pulmonary cavity. However, the ability to create a cavity in previously normal lung distinguishes $M$ tuberculosis from these opportunist infections. If $M$ tuberculosis infects organs other than the lung it will usually reach a biological dead end, killing its host and failing to spread to a new one. Surprisingly, the mechanisms by which it causes lung destruction are poorly understood. As collagen and elastin must be degraded to allow cavity formation, MMPs are likely to be involved in the pathology of TB.

\section{Animal studies}

Guinea pigs present a relatively good model of human TB, with granuloma morphology that is similar to human disease but cavitary disease rarely develops. The water soluble fraction of $M$ smegmatis can increase collagenase secretion by guinea pig macrophages, ${ }^{113}$ but more extensive analysis of MMP activity in guinea pig TB has not been undertaken. Mice are a very useful model of immunity to $M$ tuberculosis, with many findings such as the key roles of CD4+ cells, TNF$\alpha$ and IFN- $\gamma$ first identified in the mouse later confirmed in man. ${ }^{114}$ However, the pulmonary pathology of TB infection in the mouse is very different from that in humans. Mice develop progressive pulmonary fibrosis, as occurs in advanced human TB, but do not cavitate..$^{114} 115$ We hypothesise that this difference may result in part from the lack of a functional homologue of human MMP-1 in the mouse. ${ }^{107}$

In mice, $M$ tuberculosis results in increased levels of MMP-2 and MMP-9 in infected tissues ${ }^{76}$ and infection of murine macrophages increases MMP-9 secretion. ${ }^{77}$ Broad spectrum MMP inhibition in a mouse model of TB led to more rapid disease progression and a deficiency in IL-1 and IL-2 secretion with a relative excess of IL-4, demonstrating a deviation in the immune response to a Th2 profile. ${ }^{78}$ In another murine study MMP inhibition was reported to lead to reduced bloodborne $M$ tuberculosis with smaller granulomas, less cell recruitment, and more collagen deposition. ${ }^{79}$ 
This suggests that MMP activity may contribute to mycobacterial dissemination by facilitating erosion from the alveolus. However, the lack of specificity of BB-94, the MMP inhibitor used in these two studies, makes interpretation difficult. BB-94 also inhibits members of the ADAM family including ADAM-17 (TNF- $\alpha$ cleaving enzyme, TACE), so the deviated immune response may be due to inhibition of TNF- $\alpha$ release which is vital to an effective immune response to $M$ tuberculosis. ${ }^{114}$

\section{Human studies}

The first indication that MMPs may be involved in tissue destruction in TB came in 1996 when it was shown that mycobacterial lipoarabinomannan (LAM), a major antigenic cell wall component of $M$ tuberculosis, increases MMP-1 and MMP-9 gene expression in the human THP-1 cell line. ${ }^{80}$ Furthermore, MMP-9 mRNA accumulation was shown in cells isolated by BAL from two patients with active pulmonary TB. $^{80}$ Circulating MMP-9 levels correlate with disease severity of TB, with highest levels in those with the most extensive disease, while MMP-2 levels do not differ between groups. ${ }^{81}$ In an analysis of TB pleural effusions, higher levels of MMP-1, $-2,-8$ and -9 were found in patients with $\mathrm{TB}$ than in patients with congestive heart failure (unpublished data)..$^{82} 83$

In TB meningitis our group has shown a matrix degrading phenotype in the cerebrospinal fluid where increased MMP-9 concentrations are unopposed by a compensatory increase in TIMP-1 levels. ${ }^{84}$ Extensive disease occurs in TB despite a relatively low bacterial load, suggesting that host immunity and intercellular networks may drive MMP secretion. Consistent with this, the immunohistochemistry of TB lymph node granulomas shows extensive MMP-9 staining with minimal TIMP-1 expression despite the presence of only small numbers of bacilli. ${ }^{85}$ However, the ECM of the lung differs from that of brain and lymph nodes, so the key MMPs in pulmonary $\mathrm{TB}$ and extrapulmonary disease may not be the same.

We have recently studied MMP expression in pulmonary TB. In a global analysis of MMP and TIMP gene expression in $M$ tuberculosis infected human macrophages, MMP-1 and -7 were most potently upregulated. ${ }^{86}$ The induction of these specific MMPs may drive matrix destruction, as MMP-1 degrades type I collagen ${ }^{7}$ and MMP-7 is a potent elastase. ${ }^{109}$ MMP-9 gene expression and secretion was unchanged, showing that MMP regulation differs between human cell lines, undifferentiated monocytes, and macrophages. This suggests that MMP-9 expression may occur at specific phases of granuloma development. MMP-1 and -7 were expressed in caseating granulomas of patients with active culture proven TB but not in control patients. Airway epithelial cells were

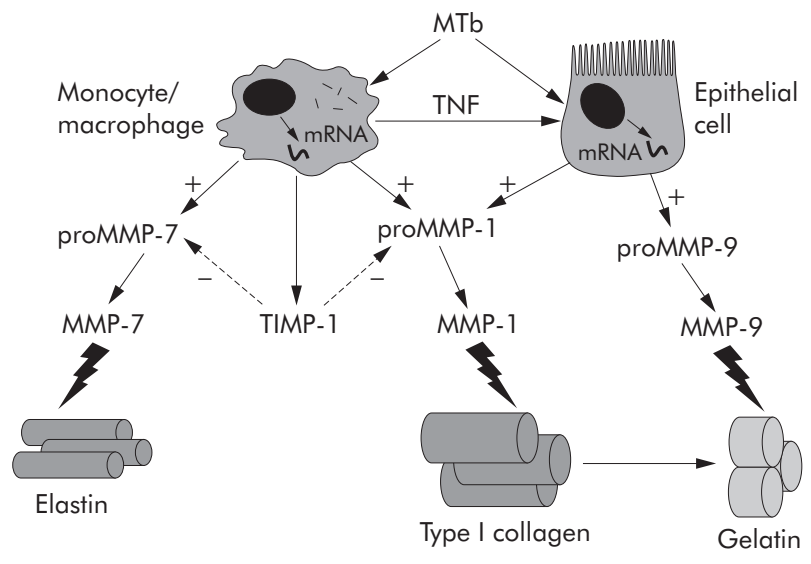

Figure 2 Schematic representation of Mycobacterium tuberculosis (MTb) driven tissue destruction. MTb infection of monocytes/ macrophages increases MMP-1 and MMP-7 gene expression and secretion. No compensatory increase in secretion of the inhibitor TIMP-1 occurs. A monocyte dependent network also drives MMP-1 and -9 secretion from pulmonary epithelial cells. After activation, MMP-1 cleaves type I collagen fibrils to gelatin which is, in turn, degraded by MMP-9 and MMP-7 degrades elastin.

also strongly immunoreactive for MMP-1, showing that stromal cells may contribute to tissue destruction (fig 1). ${ }^{87}$ In culture, epithelial cell MMP-1 expression is driven by a monocyte dependent network. $M$ tuberculosis therefore drives a matrix degrading phenotype both by direct infection of macrophages and by an intercellular network that increases MMP secretion by epithelial cells (fig 2).

\section{MMPs AS THERAPEUTIC TARGETS}

The data outlined above implicate excess MMP activity in the pathogenesis of COPD, ARDS, sarcoidosis, and TB. It therefore follows that modulating MMP activity may reduce immunopathology. The initial interest in therapeutic targeting of MMPs concentrated on cancer, although to date the results have been disappointing. ${ }^{34}$ However, in pulmonary disease, MMP inhibition can prevent pathological changes of emphysema ${ }^{47}$ and ARDS $^{69}{ }^{70}$ in animal models. In human disease, global MMP inhibition may have deleterious effects as it may suppress the key immunoregulatory functions of MMPs. Mechanisms to target specific MMPs are therefore required. This may be achieved either by generating new chemical inhibitors with a narrower spectrum of activity than those available or by targeting the pathways that regulate MMP secretion such as the mitogen activated protein kinases. In order to realise the potential of MMP inhibition

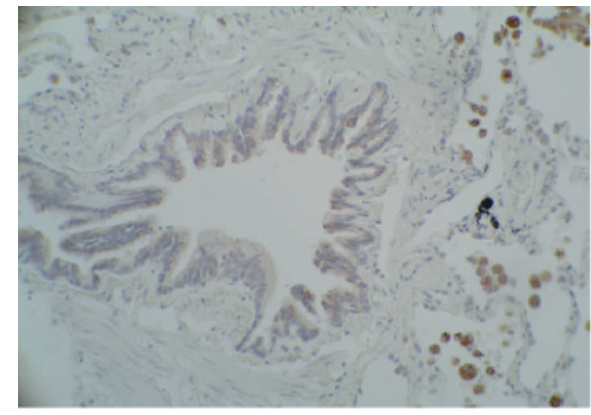

Uninfected

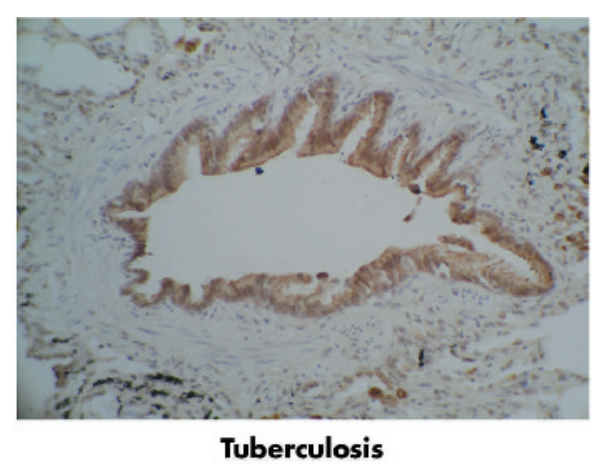

Tuberculosis

Figure 1 Pulmonary epithelial cells express MMP-1 in patients with tuberculosis. MMP-1 immunoreactivity is brown against the blue counterstain. In uninfected lung, pulmonary epithelial cells do not express MMP-1 (left panel). In active pulmonary TB epithelial cells adjacent to TB granulomas are strongly immunoreactive for MMP-1 (right panel). From Elkington et $a^{\beta 7}$ with permission. ${ }^{\odot}$ The American Association of Immunologists Inc, 2005. 
in human pulmonary disease, we must first dissect the balance between the immunological and pathological roles of critical MMPs. Next, the differences between animal models of lung disease and human disease must be further defined to ensure that animal studies of MMP inhibition reflect human disease more closely. If this can be achieved, suppression of excess MMP activity may reduce immunopathology in several pulmonary diseases.

\section{CONCLUSIONS}

MMPs are very likely to have a central role in destructive pulmonary diseases where excess proteolytic activity causes aberrant degradation of the lung ECM. Although MMPs play important roles in normal pulmonary immunity, in excess they can contribute to immunopathology that leads to morbidity and mortality. Further definition of the roles of individual MMPs in health and disease is required to allow targeted treatment that will protect the lung from excess MMP activity without compromising normal matrix remodelling and immunity.

\section{ACKNOWLEDGEMENTS}

The authors thank Dr Cecilia O'Kane and Dr Danny McAuley for critical reading of the manuscript.

\section{Authors' affiliations}

P T G Elkington, J S Friedland, Department of Infectious Diseases, Imperial College Hammersmith, London, UK

PE was a Wellcome Trust Clinical Research Training Fellow. JSF is supported by the Wellcome Trust and the Medical Reseach Council (UK) for MMP research.

The authors have no competing financial interests.

\section{REFERENCES}

1 Parks WC, Wilson CL, Lopez-Boado YS. Matrix metalloproteinases as modulators of inflammation and innate immunity. Nat Rev Immunol 2004;4:617-29.

2 Dunsmore SE, Rannels DE. Extracellular matrix biology in the lung. Am J Physiol 1996;270:L3-27.

3 Davidson JM. Biochemistry and turnover of lung interstitium. Eur Respir J 1990;3:1048-63.

4 Shapiro SD, Endicott SK, Province MA, et al. Marked longevity of human lung parenchymal elastic fibers deduced from prevalence of $D$-aspartate and nuclear weapons-related radiocarbon. J Clin Invest 1991;87:1828-34.

5 Foronjy RF, Okada Y, Cole R, et al. Progressive adult-onset emphysema in transgenic mice expressing human MMP-1 in the lung. Am J Physiol Lung Cell Mol Physiol 2003;284:L727-37.

6 Shapiro SD, Campbell EJ, Welgus HG, et al. Elastin degradation by mononuclear phagocytes. Ann NY Acad Sci 1991;624:69-80.

7 Brinckerhoff CE, Matrisian LM. Matrix metalloproteinases: a tail of a frog that became a prince. Nat Rev Mol Cell Biol 2002;3:207-14

8 Gross J, Lapiere CM. Collagenolytic activity in amphibian tissues: a tissue culture assay. Proc Natl Acad Sci USA 1962;48:1014-22.

9 Van Wart HE, Birkedal-Hansen H. The cysteine switch: a principle of regulation of metalloproteinase activity with potential applicability to the entire matrix metalloproteinase gene family. Proc Natl Acad Sci USA 1990;87:5578-82.

10 Brew K, Dinakarpandian D, Nagase H. Tissue inhibitors of metalloproteinases: evolution, structure and function. Biochim Biophys Acta 2000; 1477:267-83.

11 Parks WC, Shapiro SD. Matrix metalloproteinases in lung biology. Respir Res 2001;2:10-9

12 Campbell EJ, Cury JD, Shapiro SD, et al. Neutral proteinases of human mononuclear phagocytes. Cellular differentiation markedly alters cell phenotype for serine proteinases, metalloproteinases, and tissue inhibitor of metalloproteinases. J Immunol 1991;146:1286-93.

13 Yao PM, Buhler JM, d'Ortho MP, et al. Expression of matrix metalloproteinase gelatinases $A$ and $B$ by cultured epithelial cells from human bronchial explants. J Biol Chem 1996;271:15580-9.

14 Dunsmore SE, Saarialho-Kere UK, Roby JD, et al. Matrilysin expression and function in airway epithelium. J Clin Invest 1998;102:1321-31.

15 Mercer BA, Kolesnikova N, Sonett J, et al. Extracellular regulated kinase/ mitogen activated protein kinase is upregulated in pulmonary emphysema and mediates matrix metalloproteinase- 1 induction by cigarette smoke. J Biol Chem 2004;279:17690-6.

16 Lai WC, Zhou M, Shankavaram U, et al. Differential regulation of ipopolysaccharide-induced monocyte matrix metalloproteinase (MMP)-1 and MMP-9 by p38 and extracellular signal-regulated kinase 1/2 mitogenactivated protein kinases. J Immunol 2003;170:6244-9.

17 Reunanen N, Westermarck J, Hakkinen L, et al. Enhancement of fibroblast collagenase (matrix metalloproteinase-1) gene expression by ceramide is mediated by extracellular signal-regulated and stress-activated protein kinase pathways. J Biol Chem 1998;273:5137-45

18 Liv Z, Zhou X, Shapiro SD, et al. The serpin alphal-proteinase inhibitor is a critical substrate for gelatinase B/MMP-9 in vivo. Cell 2000;102:647-55.

19 Legrand C, Gilles C, Zahm JM, et al. Airway epithelial cell migration dynamics. MMP-9 role in cell-extracellular matrix remodeling. J Cell Biol 1999; 146:517-29.

20 Betsuyaku T, Fukuda Y, Parks WC, et al. Gelatinase B is required for alveolar bronchiolization after intratracheal bleomycin. Am J Pathol 2000; 157:525-35.

21 Faveeuw C, Preece G, Ager A. Transendothelial migration of lymphocytes across high endothelial venules into lymph nodes is affected by metalloproteinases. Blood 2001;98:688-95.

22 Warner RL, Beltran L, Younkin EM, et al. Role of stromelysin 1 and gelatinase $\mathrm{B}$ in experimental acute lung injury. Am J Respir Cell Mol Biol $2001 ; 24: 537-44$.

23 Vermaelen KY, Cataldo D, Tournoy K, et al. Matrix metalloproteinase-9mediated dendritic cell recruitment into the airways is a critical step in a mouse model of asthma. J Immunol 2003;171:1016-22.

24 Schonbeck U, Mach F, Libby P. Generation of biologically active IL-1 beta by matrix metalloproteinases: a novel caspase-1-independent pathway of IL-1 beta processing. J Immunol 1998;161:3340-6.

25 Ito A, Mukaiyama A, Itoh Y, et al. Degradation of interleukin 1 beta by matrix metalloproteinases. J Biol Chem 1996;271:14657-60.

26 Gearing AJ, Beckett $P$, Christodoulou M, et al. Processing of tumour necrosis factor-alpha precursor by metalloproteinases. Nature 1994;370:555-7.

27 Van den Steen PE, Proost P, Wuyts A, et al. Neutrophil gelatinase B potentiates interleukin-8 tenfold by aminoterminal processing, whereas it degrades CTAP-III, PF-4, and GRO-alpha and leaves RANTES and MCP-2 intact. Blood 2000;96:2673-81.

28 McQuibban GA, Gong JH, Tam EM, et al. Inflammation dampened by gelatinase A cleavage of monocyte chemoattractant protein-3. Science 2000;289:1202-6.

29 Opdenakker G, Van den Steen PE, Van Damme J. Gelatinase B: a tuner and amplifier of immune functions. Trends Immunol 2001;22:571-9.

30 Li Q, Park PW, Wilson CL, et al. Matrilysin shedding of syndecan-1 regulates chemokine mobilization and transepithelial efflux of neutrophils in acute lung injury. Cell 2002;111:635-46.

31 Boire A, Covic L, Agarwal A, et al. PAR1 is a matrix metalloprotease-1 receptor that promotes invasion and tumorigenesis of breast cancer cells. Cell 2005; 120:303-13.

32 Wilson CL, Ouellette AJ, Satchell DP, et al. Regulation of intestinal alphadefensin activation by the metalloproteinase matrilysin in innate host defense. Science 1999;286:113-7.

33 Lopez-Boado YS, Wilson CL, Parks WC. Regulation of matrilysin expression in airway epithelial cells by Pseudomonas aeruginosa flagellin. J Biol Chem 2001;276:41417-23.

34 Coussens LM, Fingleton B, Matrisian LM. Matrix metalloproteinase inhibitors and cancer: trials and tribulations. Science 2002;295:2387-92.

35 Kelly EA, Jarjour NN. Role of matrix metalloproteinases in asthma. Curr Opin Pulm Med 2003;9:28-33.

36 D'Armiento J, Dalal SS, Okada Y, et al. Collagenase expression in the lungs of transgenic mice causes pulmonary emphysema. Cell 1992;71:955-61.

37 Wang Z, Zheng T, Zhu Z, et al. Interferon gamma induction of pulmonary emphysema in the adult murine lung. J Exp Med 2000;192:1587-600.

38 Zheng T, Zhu Z, Wang Z, et al. Inducible targeting of IL-13 to the adult lung causes matrix metalloproteinase- and cathepsin-dependent emphysema. J Clin Invest 2000;106:1081-93.

39 Vuillemenot BR, Rodriguez JF, Hoyle GW. Lymphoid tissue and emphysema in the lungs of transgenic mice inducibly expressing tumor necrosis factoralpha. Am J Respir Cell Mol Biol 2004;30:438-48.

40 Wert SE, Yoshida M, LeVine AM, et al. Increased metalloproteinase activity, oxidant production, and emphysema in surfactant protein $D$ gene-inactivated mice. Proc Natl Acad Sci USA 2000;97:5972-7.

41 Shibata Y, Zsengeller Z, Otake K, et al. Alveolar macrophage deficiency in osteopetrotic mice deficient in macrophage colony-stimulating factor is spontaneously corrected with age and associated with matrix metalloproteinase expression and emphysema. Blood 2001;98:2845-52.

42 Morris DG, Huang X, Kaminski N, et al. Loss of integrin alpha(v)beta6mediated TGF-beta activation causes MMP12-dependent emphysema. Nature 2003;422:169-73.

43 Hautamaki RD, Kobayashi DK, Senior RM, et al. Requirement for macrophage elastase for cigarette smoke-induced emphysema in mice. Science 1997; 277:2002-4

44 Leco KJ, Waterhouse P, Sanchez $\mathrm{OH}$, et al. Spontaneous air space enlargement in the lungs of mice lacking tissue inhibitor of metalloproteinases-3 (TIMP-3). J Clin Invest 2001;108:817-29.

45 Lanone S, Zheng T, Zhu Z, et al. Overlapping and enzyme-specific contributions of matrix metalloproteinases -9 and -12 in IL-13-induced inflammation and remodeling. J Clin Invest 2002;1 10:463-74.

46 Selman M, Montano M, Ramos C, et al. Tobacco smoke-induced lung emphysema in guinea pigs is associated with increased interstitial collagenase. Am J Physiol 1996;271:L734-43.

47 Selman M, Cisneros-Lira J, Gaxiola M, et al. Matrix metalloproteinases inhibition attenuates tobacco smoke-induced emphysema in guinea pigs. Chest 2003;123:1633-41. 
48 Finlay GA, O'Driscoll LR, Russell KJ, et al. Matrix metalloproteinase expression and production by alveolar macrophages in emphysema. Am J Respir Crit Care Med 1997;156:240-7.

$49 \operatorname{Lim}$ S, Roche N, Oliver BG, et al. Balance of matrix metalloprotease-9 and tissue inhibitor of metalloprotease-1 from alveolar macrophages in cigarette smokers. Regulation by interleukin-10. Am J Respir Crit Care Med 2000;162:1355-60.

50 Russell RE, Culpitt SV, DeMatos $C$, et al. Release and activity of matrix metalloproteinase- 9 and tissue inhibitor of metalloproteinase- 1 by alveolar macrophages from patients with chronic obstructive pulmonary disease. Am J Respir Cell Mol Biol 2002;26:602-9.

51 Finlay GA, Russell KJ, McMahon KJ, et al. Elevated levels of matrix metalloproteinases in bronchoalveolar lavage fluid of emphysematous patients. Thorax 1997;52:502-6.

52 Betsuyaku T, Nishimura M, Takeyabu K, et al. Neutrophil granule proteins in bronchoalveolar lavage fluid from subjects with subclinical emphysema. Am J Respir Crit Care Med 1999;159:1985-91.

53 Russell RE, Thorley A, Culpitt SV, et al. Alveolar macrophage-mediated elastolysis: roles of matrix metalloproteinases, cysteine, and serine proteases. Am J Physiol Lung Cell Mol Physiol 2002;283:L867-73.

54 Segura-Valdez L, Pardo A, Gaxiola M, et al. Upregulation of gelatinases A and $B$, collagenases 1 and 2 , and increased parenchymal cell death in COPD. Chest 2000;117:684-94.

55 Ohnishi K, Takagi M, Kurokawa Y, et al. Matrix metalloproteinase-mediated extracellular matrix protein degradation in human pulmonary emphysema. Lab Invest 1998;78:1077-87.

56 Imai K, Dalal SS, Chen ES, et al. Human collagenase (matrix metalloproteinase-1) expression in the lungs of patients with emphysema. Am J Respir Crit Care Med 2001;163:786-91.

57 Grumelli S, Corry DB, Song LZ, et al. An immune basis for lung parenchymal destruction in chronic obstructive pulmonary disease and emphysema. PLoS Med 2004; 1:e8.

58 Churg A, Wang RD, Tai $\mathrm{H}$, et al. Tumor necrosis factor-alpha drives $70 \%$ of cigarette smoke-induced emphysema in the mouse. Am J Respir Crit Care Med 2004; 170:492-8.

59 Ricou B, Nicod L, Lacraz S, et al. Matrix metalloproteinases and TIMP in acute respiratory distress syndrome. Am J Respir Crit Care Med 1996;154:346-52.

60 Torii K, lida K, Miyazaki Y, et al. Higher concentrations of matrix metalloproteinases in bronchoalveolar lavage fluid of patients with adult respiratory distress syndrome. Am J Respir Crit Care Med 1997;155:43-6.

61 Pugin J, Verghese G, Widmer MC, et al. The alveolar space is the site of intense inflammatory and profibrotic reactions in the early phase of acute respiratory distress syndrome. Crit Care Med 1999;27:304-12.

62 Lanchou J, Corbel M, Tanguy M, et al. Imbalance between matrix metalloproteinases (MMP-9 and MMP-2) and tissue inhibitors of metalloproteinases (TIMP-1 and TIMP-2) in acute respiratory distress syndrome patients. Crit Care Med 2003;31:536-42.

63 Pardo A, Selman M, Ridge K, et al. Increased expression of gelatinases and collagenase in rat lungs exposed to $100 \%$ oxygen. Am J Respir Crit Care Med 1996; 154:1067-75.

64 Armstrong L, Thickett DR, Mansell JP, et al. Changes in collagen turnover in early acute respiratory distress syndrome. Am J Respir Crit Care Med 1999;160:1910-5.

65 Warner RL, Lewis CS, Beltran L, et al. The role of metalloelastase in immune complex-induced acute lung injury. Am J Pathol 2001;158:2139-44.

66 Gipson TS, Bless NM, Shanley TP, et al. Regulatory effects of endogenous protease inhibitors in acute lung inflammatory injury. $J$ Immunol 1999;162:3653-62

67 Martin EL, Moyer BZ, Pape MC, et al. Negative impact of tissue inhibitor of metalloproteinase-3 null mutation on lung structure and function in response to sepsis. Am J Physiol Lung Cell Mol Physiol 2003;285:L1222-32.

68 Carney DE, Lutz CJ, Picone AL, et al. Matrix metalloproteinase inhibitor prevents acute lung injury after cardiopulmonary bypass. Circulation 1999;100:400-6.

69 Steinberg J, Halter J, Schiller HJ, et al. Metalloproteinase inhibition reduces lung injury and improves survival after cecal ligation and puncture in rats. J Surg Res 2003;111:185-95.

70 Carney DE, McCann UG, Schiller HJ, et al. Metalloproteinase inhibition prevents acute respiratory distress syndrome. J Surg Res 2001;99:245-52.

71 O'Connor C, Odlum C, Van Breda A, et al. Collagenase and fibronectin in bronchoalveolar lavage fluid in patients with sarcoidosis. Thorax 1988:43:393-400.

72 Ward K, O'Connor CM, Odlum C, et al. Pulmonary disease progress in sarcoid patients with and without bronchoalveolar lavage collagenase. Am Rev Respir Dis 1990;142:636-41.

73 Henry MT, McMahon K, Mackarel AJ, et al. Matrix metalloproteinases and tissue inhibitor of metalloproteinase-1 in sarcoidosis and IPF. Eur Respir J 2002;20:1220-7.

74 Fireman E, Kraiem Z, Sade O, et al. Induced sputum-retrieved matrix metalloproteinase 9 and tissue metalloproteinase inhibitor 1 in granulomatous diseases. Clin Exp Immunol 2002;130:331-7.

75 Gonzalez AA, Segura AM, Horiba K, et al. Matrix metalloproteinases and their tissue inhibitors in the lesions of cardiac and pulmonary sarcoidosis: an immunohistochemical study. Hum Pathol 2002;33:1 158-64.

76 Rivera-Marrero CA, Schuyler W, Roser S, et al. Induction of MMP-9 mediated gelatinolytic activity in human monocytic cells by cell wall components of Mycobacterium tuberculosis. Microb Pathog 2000;29:231-44.
77 Quiding-Jarbrink M, Smith DA, Bancroft GJ. Production of matrix metalloproteinases in response to mycobacterial infection. Infect Immun 2001;69:5661-70.

78 Hernandez-Pando R, Orozco H, Arriaga K, et al. Treatment with BB-94, a broad spectrum inhibitor of zinc-dependent metalloproteinases, causes deviation of the cytokine profile towards type- 2 in experimental pulmonary tuberculosis in Balb/c mice. Int J Exp Pathol 2000;81:199-209.

79 Izzo AA, Izzo LS, Kasimos J, et al. A matrix metalloproteinase inhibitor promotes granuloma formation during the early phase of Mycobacterium tuberculosis pulmonary infection. Tuberculosis (Edinb) 2004;84:387-96.

80 Chang JC, Wysocki A, Tchou-Wong KM, et al. Effect of Mycobacterium tuberculosis and its components on macrophages and the release of matrix metalloproteinases. Thorax 1996;51:306-11.

81 Hrabec $E$, Strek $M$, Zieba $M$, et al. Circulation level of matrix metalloproteinase- 9 is correlated with disease severity in tuberculosis patients. Int J Tuberc Lung Dis 2002;6:713-9.

82 Hoheisel G, Sack U, Hui DS, et al. Occurrence of matrix metalloproteinases and tissue inhibitors of metalloproteinases in tuberculous pleuritis. Tuberculosis (Edinb) 2001;81:203-9.

83 Park KJ, Hwang SC, Sheen SS, et al. Expression of matrix metalloproteinase9 in pleural effusions of tuberculosis and lung cancer. Respiration 2005; 72:166-75

84 Price NM, Farrar J, Tran TT, et al. Identification of a matrix-degrading phenotype in human tuberculosis in vitro and in vivo. J Immunol 2001;166:4223-30.

85 Price NM, Gilman RH, Uddin J, et al. Unopposed matrix metalloproteinase-9 expression in human tuberculous granuloma and the role of TNF-alphadependent monocyte networks. J Immunol 2003;171:5579-86.

86 Elkington PTG, Nuttall RK, Boyle JJ, et al. Mycobacterium tuberculosis but not vaccine $B C G$ specifically up-regulates matrix metalloproteinase-1. Am J Respir Crit Care Med 2006 (in press).

87 Elkington PTG, Emerson JE, Lopez-Pascua LDC, et al. Mycobacterium tuberculosis up-regulates matrix metalloproteinase- 1 secretion from human airway epithelial cells via a p38 MAPK switch. J Immunol $2005 ; 175: 5333-40$.

88 Rivera-Marrero CA, Schuyler W, Roser S, et al. M. tuberculosis induction of matrix metalloproteinase-9: the role of mannose and receptor-mediated mechanisms, Am J Physiol Lung Cell Mol Physiol 2002;282:L546-55.

89 Fukuda $Y$, Ishizaki $M$, Kudoh S, et al. Localization of matrix metalloproteinases-1, -2 , and -9 and tissue inhibitor of metalloproteinase-2 in interstitial lung diseases. Lab Invest 1998;78:687-98.

90 Suga $\mathrm{M}$, lyonaga $\mathrm{K}$, Okamoto $\mathrm{T}$, et al. Characteristic elevation of matrix metalloproteinase activity in idiopathic interstitial pneumonias. Am J Respir Crit Care Med 2000; 162: 1949-56.

91 Kim KH, Burkhart K, Chen P, et al. Tissue inhibitor of MP-1 deficiency amplifies acute lung injury in bleomycin exposed mice. Am J Respir Cell Mol Biol 2005; 33:271-9.

92 Selman M, Ruiz V, Cabrera S, et al. TIMP-1, -2, -3, and -4 in idiopathic pulmonary fibrosis. A prevailing nondegradative lung microenvironment? Am J Physiol Lung Cell Mol Physiol 2000;279:L562-74.

93 Lemiabbar H, Gosset $P$, Lechapt-Zalcman $E$, et al. Overexpression of alveolar macrophage gelatinase $B$ (MMP-9) in patients with idiopathic pulmonary fibrosis: effects of steroid and immunosuppressive treatment. Am J Respir Cell Mol Biol 1999;20:903-13.

94 Perez-Ramos J, de Lourdes Segura-Valdez M, Vanda B, et al. Matrix metalloproteinases 2, 9, and 13, and tissue inhibitors of metalloproteinases 1 and 2 in experimental lung silicosis. Am J Respir Crit Care Med $1999 ; 160: 1274-82$

95 Ratien F, Hartog CM, Paul K, et al. Matrix metalloproteases in BAL fluid of patients with cystic fibrosis and their modulation by treatment with dornase alpha. Thorax 2002;57:930-4.

96 Sagel SD, Kapsner RK, Osberg I. Induced sputum matrix metalloproteinase-9 correlates with lung function and airway inflammation in children with cystic fibrosis. Pediatr Pulmonol 2005;39:224-32.

97 Hartog CM, Wermelt JA, Sommerfeld CO, et al. Pulmonary matrix metalloproteinase excess in hospital-acquired pneumonia. Am J Respir Crit Care Med 2003; 167:593-8.

98 Hayashi T, Fleming MV, Stetler-Stevenson WG, ef al. Immunohistochemical study of matrix metalloproteinases (MMPs) and their tissue inhibitors (TIMPs) in pulmonary lymphangioleiomyomatosis (LAM). Hum Pathol 1997;28:1071-8.

99 Zhe X, Yang Y, Jakkaraju S, et al. Tissue inhibitor of metalloproteinase-3 downregulation in lymphangioleiomyomatosis: potential consequence of abnormal serum response factor expression. Am J Respir Cell Mol Biol 2003;28:504-11.

100 Choi KH, Lee HB, Jeong MY, et al. The role of matrix metalloproteinase-9 and tissue inhibitor of metalloproteinase- 1 in cryptogenic organizing pneumonia. Chest 2002;121:1478-85.

101 Taghavi S, Krenn K, Jaksch P, et al. Broncho-alveolar lavage matrix metalloproteases as a sensitive measure of bronchiolitis obliterans. Am J Transplant 2005;5:1548-52.

102 Hubner RH, Meffert S, MundtU, et al. Matrix metalloproteinase-9 in bronchiolitis obliterans syndrome after lung transplantation. Eur Respir J 2005;25:494-501.

103 Hayashi T, Rush WL, Travis WD, et al. Immunohistochemical study of matrix metalloproteinases and their tissue inhibitors in pulmonary Langerhans' cell granulomatosis. Arch Pathol Lab Med 1997;121:930-7.

104 Araya J, Maruyama M, Sassa K, et al. lonizing radiation enhances matrix metalloproteinase-2 production in human lung epithelial cells. Am J Physiol Lung Cell Mol Physiol 2001;280:L30-8.

105 Lomas DA, Mahadeva R. Alphal-antitrypsin polymerization and the serpinopathies: pathobiology and prospects for therapy. J Clin Inves 2002;110:1585-90. 
106 Barnes PJ. Mediators of chronic obstructive pulmonary disease. Pharmacol Rev 2004;56:515-48.

107 Balbin M, Fueyo A, Knauper V, et al. Identification and enzymatic characterization of two diverging murine counterparts of human interstitial collagenase (MMP-1) expressed at sites of embryo implantation. J Biol Chem 2001;276:10253-62.

108 Churg A, Wright JL. Proteases and emphysema. Curr Opin Pulm Med 2005;11:153-9.

109 Filippov S, Caras I, Murray R, et al. Matrilysin-dependent elastolysis by human macrophages. J Exp Med 2003;198:925-35.

110 Atkinson JJ, Senior RM. Matrix metalloproteinase-9 in lung remodeling. Am J Respir Cell Mol Biol 2003;28:12-24.
111 Ware LB, Matthay MA. The acute respiratory distress syndrome. NEng/ J Med 2000;342:1334-49.

112 Kaplan G, Post FA, Moreira AL, et al. Mycobacterium tuberculosis growth at the cavity surface: a microenvironment with failed immunity. Infect Immun 2003;71:7099-108.

113 Wahl SM, Wahl LM, McCarthy JB, et al. Macrophage activation by mycobacterial water soluble compounds and synthetic muramyl dipeptide. J Immunol 1979; 122:2226-31.

114 North RJ, Jung YJ. Immunity to tuberculosis. Annu Rev Immunol 2004;22:599-623.

115 Orme IM. The immunopathogenesis of tuberculosis: a new working hypothesis. Trends Microbiol 1998;6:94-7.

\section{Committee on Publication Ethics - Seminar 2006}

\subsection{0am-5pm Friday 10th March 2006, BMA House, London, UK}

This year's seminar takes an international perspective and addresses publication ethics and research in several European countries and beyond, with interactive workshops on common ethical and editorial dilemmas. The manipulation of impact factors, and whether unethical, will also be considered.

The seminar is for editors, authors, and all those interested in increasing the standard of publication ethics. The seminar will include:

- Professor Michael Farthing - the Panel for Research Integrity (UK)

- Publication ethics and research in other countries, including those in Northern Europe, Turkey, and China

- Publication ethics in animal research

- Making the COPE website work for you - real time demonstration on how to use the website

- New indexing services

- Interactive workshops - common ethical and editorial dilemmas for editors

- Opportunities to network with other editors and share your experiences and challenges The seminar is free for COPE members and $£ 30.00+$ VAT for non-members. Numbers are limited and early booking is advisable. For registrations or more information please contact the COPE Secretary at cope@bmigroup.com or call 020-7383-6602

For more information on COPE see www.publicationethics.org.uk 